\title{
Study on Total Factor Carbon Emission Efficiency in the Yangtze River Economic Zone, China
}

\author{
Jiwen Chen, Zuxu Zou* \\ School of Civil Engineering and Architecture, Wuhan Polytechnic University, Wuhan 430023, China
}

\begin{abstract}
With the continuous acceleration of the modernization process, the Eco-environmental problems of the Yangtze River Economic Zone in China have become increasingly prominent, which makes the study of carbon emission efficiency become a long-term concern. Based on the panel data of 11 provinces and cities of the Yangtze River Economic Zone in 2009 2016, this paper calculates the DEA-Malmquist index of the Total Factor Carbon Emission Efficiency containing undesirable output in various provinces and cities and three major regions. By studying the DEA-Malmquist index and its decomposition, the results show that the Total Factor Carbon Emission Efficiency of various regions in the Yangtze River Economic Zone presents a growth trend, and its main contribution comes from technological progress. In the future, the emission reduction rules of the Yangtze River Economic Zone will be transformed from the traditional top-down emission reduction model to the bottom-up "independent contribution" emission reduction model.
\end{abstract}

\section{Introduction}

The Yangtze River Economic Zone stretches across the Eastern, Central and Western China, thus has a very important strategic position. With the population and GDP exceeding $40 \%$ of the whole nation, the Yangtze River Economic Zone has many problems to be solved, including ecological rehabilitation ${ }^{[1]}$. In order to promote green and sustainable development of the Yangtze River Economic Zone, it is an essential proposition to study carbon emission efficiency in the Yangtze River Economic Zone.

Currently, the definition of carbon emission efficiency mainly includes two concepts: Single Factor Carbon Emission Efficiency (SFCEE) and Total Factor Carbon Emission Efficiency (TFCEE). The SFCEE is meant by the ratio of two variables from a single factor perspective. The calculation methods of it mainly include carbon productivity, carbon index, and carbon emissions unit GDP, etc. However, due to the diversity of its measurement indicators, there are many controversies, and some scholars have integrated multiple factors to construct a more comprehensive Total Factor Index. Nonparametric Methods and Parametric Methods are used to measure the TFCEE. Zaim and Taskin first regarded carbon emissions as undesired outputs, and proposed a comprehensive carbon emission assessment index to study carbon emission performance in OECD countries ${ }^{[2]}$. Du et al. used SFA method to measure the carbon dioxide emission efficiency of various provinces and cities in China $^{[3]}$. Ramanathan used DEA method to analyze the fluctuation of carbon emissions over time in 17 countries $^{[4]}$. Zhou used different DEA methods including SBM models when measuring carbon emission efficiency in OECD countries ${ }^{[5-7]}$. Lu et al. analyzed the trend of carbon emission efficiency of China's provincial construction industry and classified them ${ }^{[8]}$. In this paper, DEA model and Malmquist index are coupled to analyze the time-series evolution of TFCEE in 11 provinces and cities in the Yangtze River Economic Zone.

\section{Data and methods}

\subsection{The DEA- Malmquist index model}

The Malmquist Index was proposed by Malmquist ${ }^{[9]}$, and Caves et al. first applied the Malmquist Index to examine productivity ${ }^{[10]}$. Fare et al. combined the Malmquist index with the DEA theory, and then used the distance function to decompose the Malmquist index into the Efficiency Change index (EC) and the Technology Change index (TC) ${ }^{[11]}$. The Malmquist index based on DEA method can be expressed as:

$$
\begin{aligned}
M\left(x^{t}, y^{t}, x^{t+1}, y^{t+1}\right)=\frac{D^{t+1}{ }_{i}\left(x^{t+1}, y^{t+1}\right)}{D^{t}{ }_{i}\left(x^{t}, y^{t}\right)} & \\
& \times\left[\frac{D^{t}{ }_{i}\left(x^{t}, y^{t}\right)}{D^{t+1}{ }_{i}\left(x^{t}, y^{t}\right)} \times \frac{D^{t}{ }_{i}\left(x^{t+1}, y^{t+1}\right)}{D^{t+1}{ }_{i}\left(x^{t+1}, y^{t+1}\right)}\right]^{\frac{1}{2}}
\end{aligned}
$$

where $\left(\mathrm{x}^{\mathrm{t}}, \mathrm{y}^{\mathrm{t}}\right)$ and $\left(\mathrm{x}^{\mathrm{t}+1}, \mathrm{y}^{\mathrm{t}+1}\right)$ are Input and Output Vectors for period $t$ and $(t+1)$ respectively, $D_{i}^{t}$ and $\mathrm{D}^{\mathrm{t}+1}{ }_{\mathrm{i}}$ are Distance Functions for period $\mathrm{t}$ and $(\mathrm{t}+1)$ respectively, the first half is the Efficiency Change index, and the latter half is the Technology Change index. Change of TFCEE is represented by the Malmquist index, which is marked as MCPI. "MCPI $>1$ " indicates that productivity increases, otherwise productivity decreases. The Efficiency Change index reflects the advantage or

\footnotetext{
*Corresponding author: 402307895@qq.com
} 
otherwise of carbon emission reduction management and policy structure, and the Technology Change index reflects the level of technological progress of energy conservation and emission reduction from period $\mathrm{t}$ to $(\mathrm{t}+1)$.

\subsection{The DEA-Malmquist model index system}

The quantity of employment in the second industry is selected as the labor input; the total energy consumption of each province is taken as energy input; the total fixed assets investment is regarded as capital input; the GDP is used as expected output; the amount of carbon emissions is taken as the undesired output. Taking coal, crude oil and natural gas as evaluation objects to estimate carbon emissions, the formula for calculating carbon emissions is as follows:

$$
\mathrm{C}=\sum \beta_{i} \rho_{i} E_{i}
$$

where $\mathrm{C}$ denotes total carbon emissions, $\beta_{\mathrm{i}}$ is the coefficient of energy i converting to standard coal, $\rho_{\mathrm{i}}$ is the carbon emission coefficient of energy $i$, and $E_{i}$ denotes the consumption of energy i. Besides, the coefficient of conversion to standard coal comes from the "China Energy Statistical Yearbook", and the carbon emission coefficient derives from "Guidelines for National Greenhouse Gas Emissions Inventories" issued by IPCC in 2006. Relevant indicators of various energy sources are shown in Table 1:

Table 1. Coefficient related to carbon emissions of various energy sources

\begin{tabular}{l|ccc}
\hline energy & coal crude oil & natural \\
& & & gas \\
\hline the coefficient of & & & \\
conversion to standard coal & 0.7143 & 1.4286 & 13.3 \\
$\left(10 \mathrm{ktce} / 10 \mathrm{kt}, 100 \mathrm{M} \mathrm{m}^{3}\right)$ & & & \\
carbon emission coefficient & & & \\
$(10 \mathrm{kt} / 10 \mathrm{ktce})$ & 0.7559 & 0.5857 & 0.4483 \\
\hline
\end{tabular}

\subsection{Data source}

All the research data are derived from the "Guidelines for National Greenhouse Gas Emissions Inventories", the "China Statistical Yearbook", the Statistical Yearbooks of various provinces, the "Statistical Bulletin on National Economic and Social Development" and so on.

\section{Results and analysis}

\subsection{The dynamic change of carbon emissions}

Formula (2) is utilized to calculate the total carbon emissions and the carbon emissions of different provinces and cities in the Yangtze River Economic Zone (Fig 1, 2). The data show that the total carbon emissions soared in 2009 2011 and tend to change slowly in recent years. Furthermore, there are differences in changes of carbon emissions in various provinces and cities. For one thing, the carbon emissions of Jiangsu are much higher than those in other provinces and cities and increase rapidly in the sample year, while the carbon emissions of Jiangxi and Chongqing are the lowest. For another, the carbon emissions of Jiangsu, Anhui and Jiangxi show an increasing trend, and the carbon emissions of Yunnan show a decreasing trend. In a word, with the continuous development of the economy, most of the provinces and cities have relatively stable carbon emissions, while energy-saving and emission-reduction effects of Jiangsu are not satisfactory, and its management of carbon emissions needs special attention from the government. Jiangsu is the largest petrochemical base in the south of China with the total amount of machinery industry exceeding that of all other provinces and the total amount of industrial exhaust emissions remaining high, resulting in much higher total carbon emissions than other provinces and cities.

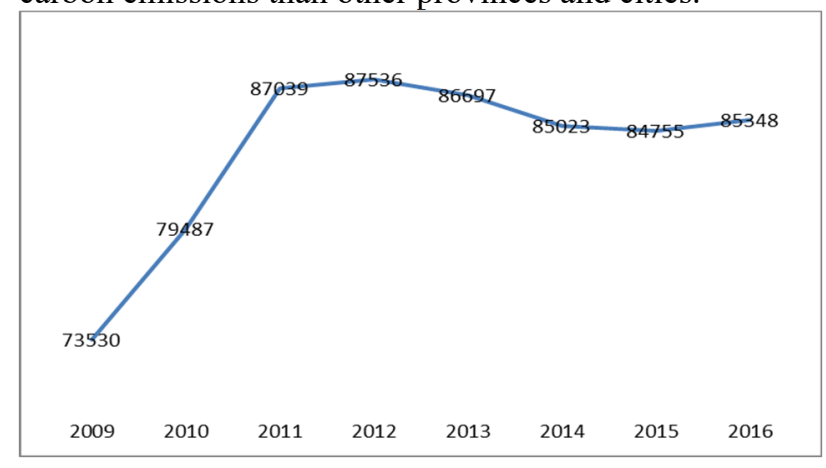

Fig.1. Total carbon emissions of the Yangtze River Economic Zone (10 kt)

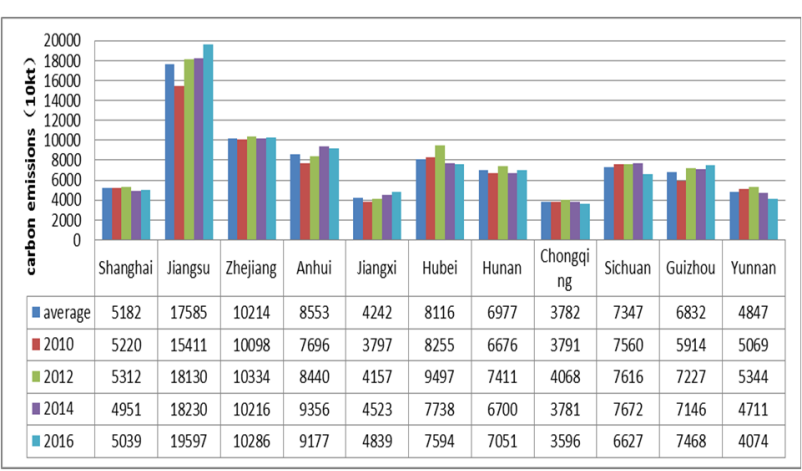

Fig.2. Carbon emissions of various provinces and cities of the Yangtze River Economic Zone (10 kt)

\subsection{Temporal evolution and internal influencing factors of TFCEE}

Computing results of DEA-Malmquist index of TFCEE are presented in Tab 2 and Fig 3. As showed in Tab 2, the TFCEE Index of the Yangtze River Economic Zone is generally more than 1 during the sample period, which 
indicates that the overall TFCEE shows an increasing trend. In addition, Shanghai's TFCEE is the best, thanks to its optimal level of scientific and technological progress, Hubei and Hunan have the lowest TFCEE index, and Yunnan's increasing range of TFCEE is not prominent but the growth trend is the most stable. In Fig 3 , as a whole, the TFCEE indexes of the Yangtze River Economic Zone and its three regions show a wavy change. The TFCEE index of Upper Yangtze River peaked in 2012 2013, the TFCEE index of Middle Yangtze River is the most stable, and the TFCEE index of Lower Yangtze River has shown a small wave change since plunging from the peak of TFCEE index in 2009 2010. In recent years, the TFCEE index of the three regions fluctuated slightly and similarly. The Lower Yangtze River has the largest total carbon emissions, but its carbon emission efficiency far exceeds the Upper and Middle Yangtze River from 2009 to 2010. Due to the flat terrain, convenient transportation, good natural conditions, superior investment environment and abundant human resources, the economic aggregate of the Lower Yangtze River is extremely large.

The decomposition results of the TFCEE index (Tab 3) show that the Technology Change index of various provinces and cities is basically greater than the Efficiency Change index and more than 1, and only the Efficiency Change index of Zhejiang and Chongqing is less than 1. It is analyzed as follows: firstly, the increase of TFCEE is mainly due to Technology Change and yet the role of Efficiency Change is less, which manifest that the operation and development of scientific and technological innovation has played an active role in promoting the level of TFCEE in the Yangtze River Economic Zone, and the technical efficiency needs to be improved. Secondly, diversity of TFCEE of various provinces mainly lies in the differences in Technology Change, and the diversity of Efficiency Change is little. Thirdly, the Technology Change has played a positive role in promoting the level of TFCEE in 11 provinces and cities; most of the provinces and cities have a good technical efficiency level, except that the Efficiency Change of Zhejiang and Chongqing has an inhibitory effect on the improvement of TFCEE. Especially, as the core of the development of the Yangtze River Economic Zone, Chongqing should be paid sufficient attention to strengthen the resource allocation of carbon emission-reduction and improve policy management.

Table 2. the TFCEE Index

\begin{tabular}{|c|c|c|c|c|c|c|c|c|}
\hline time & $\begin{array}{c}2009 \sim \\
2010 \\
\end{array}$ & $\begin{array}{c}2010 \sim \\
2011 \\
\end{array}$ & $\begin{array}{c}2011 \sim \\
2012 \\
\end{array}$ & $\begin{array}{c}2012 \sim \\
2013 \\
\end{array}$ & $\begin{array}{c}2013 \sim \\
2014 \\
\end{array}$ & $\begin{array}{c}2014 \sim \\
2015 \\
\end{array}$ & $\begin{array}{c}2015 \sim \\
2016 \\
\end{array}$ & average \\
\hline Shanghai & 1.556 & 1.0315 & 1.0555 & 0.9943 & 1.1198 & 1.0493 & 1.0896 & 1.128 \\
\hline Jiangsu & 1.3301 & 1.0536 & 1.038 & 1.0275 & 1.0776 & 1.0299 & 1.0475 & 1.0863 \\
\hline Zhejiang & 1.2475 & 1.0984 & 1.0599 & 1.0492 & 1.0524 & 1.025 & 1.0636 & 1.0851 \\
\hline Guizhou & 1.029 & 1.0225 & 1.0151 & 1.4857 & 0.9001 & 1.097 & 1.0108 & 1.08 \\
\hline Jiangxi & 1.173 & 1.158 & 1.0578 & 1.0376 & 1.0372 & 1.0153 & 1.0564 & 1.0765 \\
\hline Sichuan & 1.0786 & 1.0979 & 1.0457 & 1.0583 & 1.0221 & 1.0763 & 1.0571 & 1.0623 \\
\hline Chongqing & 1.0451 & 1.0615 & 1.0764 & 1.1011 & 1.0227 & 1.0428 & 1.0782 & 1.0611 \\
\hline Anhui & 1.0816 & 1.0868 & 1.0436 & 1.0614 & 1.0519 & 1.0275 & 1.0599 & 1.059 \\
\hline Yunnan & 1.0319 & 1.0555 & 1.0429 & 1.0516 & 1.0745 & 1.0681 & 1.0479 & 1.0532 \\
\hline Hunan & 1.064 & 1.0231 & 1.073 & 1.0792 & 1.0645 & 1.0168 & 1.0265 & 1.0496 \\
\hline Hubei & 1.0099 & 1.0229 & 1.0492 & 1.1377 & 1.0445 & 1.0366 & 1.0444 & 1.0493 \\
\hline average & 1.1497 & 1.0647 & 1.0507 & 1.0986 & 1.0425 & 1.0441 & 1.0529 & 1.0719 \\
\hline
\end{tabular}

Table 3. the decomposition of TFCEE Index

\begin{tabular}{ccccccccccccc}
\hline regions & Shanghai & Jiangsu & Zhejiang & Guizhou & Jiangxi & Sichuan & Chongqing & Anhui & Yunnan & Hunan & Hubei & average \\
\hline MCPI & 1.128 & 1.0863 & 1.0851 & 1.08 & 1.0765 & 1.0623 & 1.0611 & 1.059 & 1.0532 & 1.0496 & 1.0493 & 1.0719 \\
EC & 1 & 1 & 0.9948 & 1.0409 & 1.0006 & 1.0272 & 0.994 & 1.0048 & 1.0251 & 1.0145 & 1.0171 & 1.0108 \\
TC & 1.128 & 1.0863 & 1.0907 & 1.0673 & 1.0753 & 1.0356 & 1.0735 & 1.0539 & 1.0279 & 1.0356 & 1.0327 & 1.0643 \\
\hline
\end{tabular}

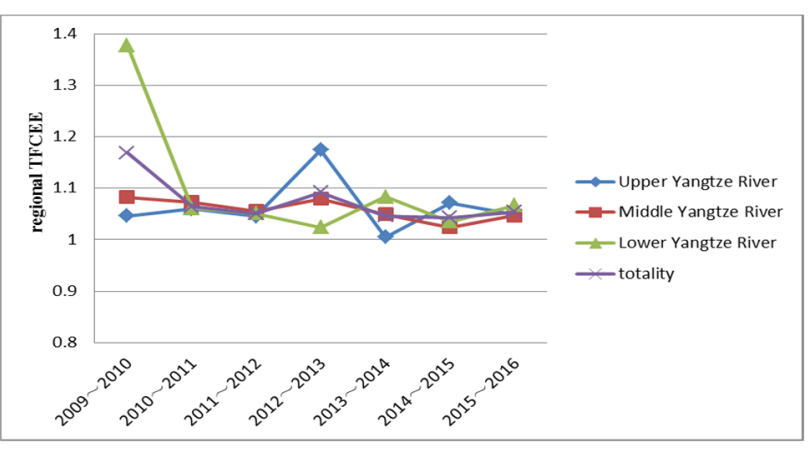

Fig.3. line graph of regional TFCEE

\section{Conclusions}

(1) According to the calculation results of carbon emissions and TFCEE in the Yangtze River Economic Zone, carbon emissions increase sharply from 2009 to 2012, and with the implementation of various energy-conservation and emission-reduction policies and the development of low-carbon technologies, the carbon emissions of 2012 2016 show a downward trend, and the TFCEE is also increasing slowly. On the whole, it is judged that the carbon emission of Yangtze River Economic Zone is located near the inflexion of the 
environmental Kuznets curve (EKC) and the carbon peak can be reached in recent years.

(2) The results of internal influencing factors of TFCEE decomposition show that main contribution to the growth of TFCEE comes from the advancement of science and technology, the Technology Change of 11 provinces and cities has played a positive role in different degrees, and the Efficiency Change has a negative impact on Zhejiang, Chongqing and Lower Yangtze River.

\section{Acknowledgments}

This work is supported by the Philosophical and Social Sciences Research Project of Hubei Education Department in 2019, which named "The establishment and research of the influencing factors and combined forecasting models of carbon emissions in Hubei Province under the New Economic Normality" (No.19Y078).

\section{References}

1. Liu Yi, Zhou Chenghu, Wang Chuansheng, et al. Issues and suggestions on the construction of the Yangtze River Economic Belt[J]. Progress in Geography, 2015, 34(11): 1345-1355.

2. Zaim O, Taskin F. Environmental efficiency in carbon dioxide emissions in the OECD: a non-parametric approach[J]. Journal of Environmental Management, 2000, 58(2): 95-107.

3. Du Kerui, Zou Chuyuan. Analysis of regional differences, influencing factors and convergence of carbon emission efficiency in China: An Empirical Study Based on Stochastic Frontier Model and panel unit $\operatorname{root}[\mathrm{J}]$. Zhejiang Social Sciences, 2011(11): $32-43+156$

4. Ramanathan R. A multi-factor efficiency perspective to the relationships among world GDP, energy consumption and carbon dioxide emissions[J]. Technological Forecasting and Social Change, 2006, 73(5): 483-494.

5. Zhou P, Ang B W, Poh K L. Slacks-based efficiency measures for modeling environmental performance[J]. Ecological Economics, 2006, 60(1): 111-118.

6. Zhou P, Ang B W, Poh K L. A survey of data envelopment analysis in energy and environmental studies $[\mathrm{J}]$. European Journal of Operational Research, 2008, 189(1): 1-18.

7. Zhou P, Ang B W, Han J Y. Total factor carbon emission performance: a Malmquist index analysis[J]. Energy Economics, 2010, 32(1): 194-201.

8. Lu Ning, Yang Wenjun, Ding Rong, et al. Study on Diversity Analysis and Research into Carbon Efficiency of Construction Industry in China's 30 Provinces from 2008 to 2012[J]. Resource Development \& Market, 2015, 31(06): 718-721.
9. Malmquist S. Index numbers and indifference surfaces[J]. Trabajos de estadística, 1953, 4(2): 209-242.

10. Caves D W, Christensen L R, Diewert W E. Multilateral comparisons of output, input, and productivity using superlative index numbers[J]. The economic journal, 1982, 92(365): 73-86.

11. Fare R, Grosskopf S, Norris M, et al. Productivity growth, technical progress, and efficiency change in industrialized countries[J]. American economic review, 1994, 84(1): 66-83. 